\title{
TYPE ROLE OF MECHANICAL ENGINEERS IN SUSTAINABLE DEVELOPMENT
}

\author{
Mustafizur Rahman \\ Department of Mechanical Engineering, National University of Singapore.
}

\begin{abstract}
For development to be sustainable, it should be able to meet the needs of the present without compromising the ability of future generations to meet their own needs. Generally, development is considered unsustainable when insufficient attention is paid to the economic, environmental and social consequences. A prerequisite for development is growth and that is directly related to production or output of a country. If production is done via a sustainable path it can maintain the sustainability of development. Mechanical and Manufacturing Engineers predominantly shoulder manufacturing. As mechanical engineering is somewhat considered the "merging ground" of all forms of engineering, the level of mechanical engineering can be a reliable barometer for measuring the development in a country. Thus mechanical engineers play a vital role in development in countries across the globe. This paper highlights the role, responsibilities and necessary contributions required by mechanical engineers to achieve sustainable development in time.
\end{abstract}

Key Words: Mechanical Engineers, Sustainable Development, Manufacturing.

\section{INTRODUCTION}

The term sustainable development focuses attention on intergenerational equity along economic, environmental as well as social issues. A widely accepted definition of sustainable development is "development which meets the needs of the present without compromising the ability of future generations to meet their own needs" [1]. Generally, development is considered unsustainable when insufficient attention is paid to the environmental consequences especially. Before elaborating further about sustainable development, it is important to establish a key point: economists generally consider economic growth as a prerequisite for development. Economic growth on it's own does not necessarily imply development as a country may grow without any development objective being achieved. On the other hand, development necessitates growth, as developing countries need an increase in their total economic output to be able to afford making progress on the development front. Sustainability is crucial so as to ensure future generations are not neglected when present-day governmental planning and economic production is carried out. There should always be a balance whereby needs of the present are met without jeopardizing the standard of living of the generations to come, so as to avoid threatening their survival.

In this paper, the main components of sustainable development that will be discussed are, economic, environmental and social sustainability (Fig. 1); what each particular sustainability means and why it is important to work towards them, and how mechanical engineers play a pivotal role in achieving sustainable development.

\section{Sustainable Development}

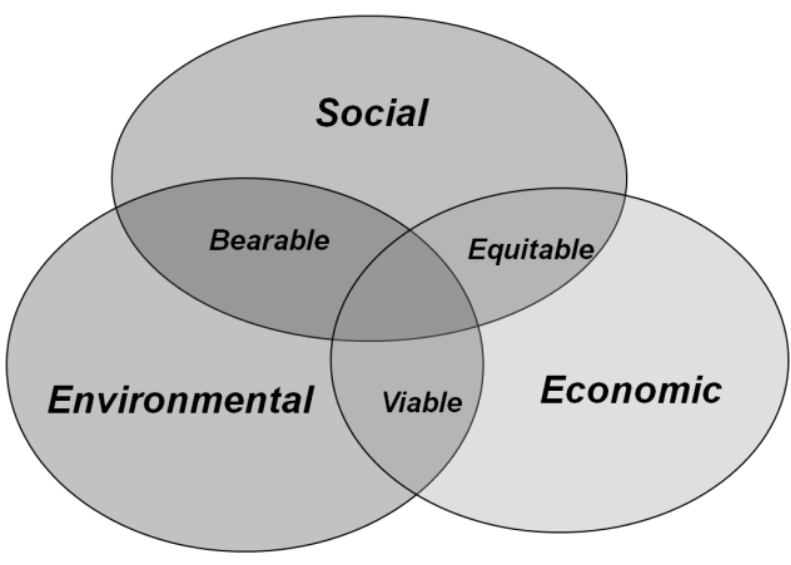

Sustainable Manufacturing

Figure 1. Major components of sustainable development.

\section{COMPONENTS OF SUSTAINABLE DEVELOPMENT}

\section{Economic Sustainability}

As mentioned earlier, the need for growth is paramount in achieving economic development and therefore economic sustainability. It should also be noted that poverty is a very significant barrier to growth and Bangladesh is no stranger to it. Poverty therefore, is the foremost major obstacle for Bangladesh to overcome in her bid to attain sustainable development. With the aid of the poverty trap cycle diagram shown below, it can be seen how low economic growth can have harmful knock-on effects, which hampers development (Fig.2). 


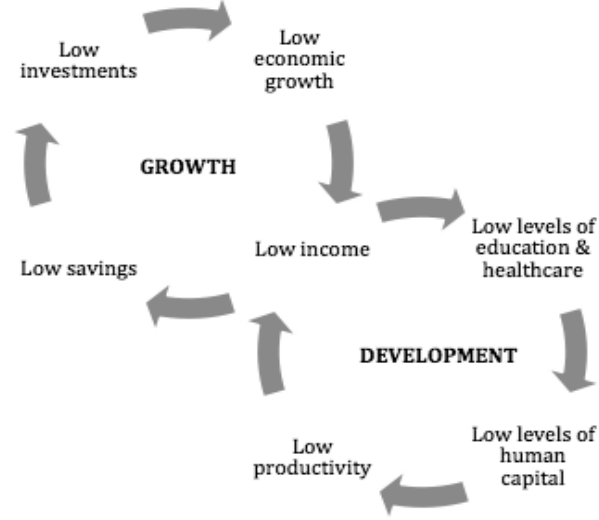

Figure 2. Poverty Trap Cycle.

Firstly, this paper shall establish how low income of those stricken by poverty in Bangladesh hinders her economic growth. Of the 135 million people living in Bangladesh, $50 \%$ of the population lives below the poverty line of US $\$ 1.25$ per day [2]. This emphasizes the depth of the number of Bangladeshis who have such low levels of income. It is therefore not surprising that they have low levels of savings and thus banks and organizations cannot help but make low levels of investments into the economy, which results in low economic growth. This brings about a vicious cycle of low economic growth, which is hard to climb out of.

The second establishment this paper shall construct is the effects a low level of income has on Bangladesh's development. Low levels of income of households lower the propensity of locals to spend on their children's education and their family's general healthcare. This results in low human capital as the number of healthy and able people in Bangladesh's workforce is fewer than it could have been. Hence, there is low productivity in the economy as economic output suffers, which leaves no choice but to give low wages to the workforce. In turn, intensifying the vicious cycles by branching low economic growth out, to low levels of development in the country as a result of the former.

\section{Environmental Sustainability}

Environmental and economic issues are inseparably interlinked and these must go hand in hand otherwise one will be a hindrance to the other. Production meets the needs of the global population, be it capital goods or consumer goods. However, this comes at a cost - the environment is sacrificed for every good that is produced; deforestation is rampant and carbon emission is increasing annually. These are just some of the examples of how the Earth is being damaged gradually.

The Tables 1 and 2 are illustrations of how harmful "careless" production has been to the environment. Deforestation has been increasing every year, causing the carbon cycle to be disrupted. Lesser trees would mean lesser carbon dioxide is used for photosynthesis resulting in lesser oxygen released into the atmosphere. While affecting the general air quality, a more prevalent natural calamity has taken root - global warming.

From Table 2, it can be seen that carbon emission is increasing every year. Coupled with deforestation, the natural environment is unable to cope with the increasing levels of carbon dioxide and other greenhouse gases. These greenhouses gases therefore create a layer around the atmosphere and block reflected heat from exiting atmosphere. Hence giving rise to global warming.

Global warming has seen the average temperature of the Earth rise substantially over the last couple of decades (figure 3 ). The consequential melting of glaciers for instance has caused water levels to rise annually, threatening the livelihood of millions of people around the world as countries could soon be submerged.

Kutubdia, an island 15 kilometers off the famed coastal town of Cox's Bazar in Bangladesh, has seen the disastrous effects of rising sea levels. The island has shrunk from 250 kilometers to 37 kilometers in the last century, leaving its inhabitants nowhere to go. According to the Meteorological Research Centre of the South Asian Association for Regional Cooperation, the coast is rising 4 millimetres per year at Hiron Point, $6 \mathrm{~mm}$ at Char Changa, and $7.8 \mathrm{~mm}$ at Cox's Bazar. And given the present rate of rise, estimates by the United Nations Development Program (UNDP) has suggested that Bangladesh may lose 15 to 18 percent of its land area and 30 million people may become "environmental refugees" [3]. It is therefore of paramount importance that the people and the Bangladeshi government look inward at the devastating effect global warming has on Bangladesh. The problem is present and prevalent and has to be dealt with by the Bangladeshi administrations in power, political differences left aside.

Table 1 - Annual rate of deforestation [4]

\begin{tabular}{|l|r|r|r|r|c|}
\hline & \multirow{2}{*}{$\begin{array}{l}\text { Number of } \\
\text { countries }\end{array}$} & \multicolumn{2}{|c|}{$\begin{array}{c}\text { Forest cover } \\
\text { (million ha) }\end{array}$} & \multicolumn{2}{|c|}{$\begin{array}{c}\text { Annual deforestation } \\
\text { (1981-91) }\end{array}$} \\
\cline { 3 - 6 } & & 1980 & 1990 & million ha & $\begin{array}{c}\% \text { per } \\
\text { annum }\end{array}$ \\
\hline Africa & 40 & 568.6 & 527.6 & 4.1 & 0.7 \\
\hline West Sahelian Africa & 6 & 43.7 & 40.8 & 0.3 & 0.7 \\
East Sahelian Africa & 9 & 71.4 & 65.5 & 0.6 & 0.9 \\
West Africa & 8 & 61.5 & 55.6 & 0.6 & 1.0 \\
Central Africa & 6 & 215.5 & 204.1 & 1.1 & 0.5 \\
Tropical Southern Africa & 10 & 159. & 145.9 & 1.3 & 0.9 \\
Insular Africa & 1 & 17.1 & 15.8 & 0.1 & 0.8 \\
\hline Asian and Pacific & 17 & 349.6 & 310.6 & 3.9 & 1.2 \\
\hline South Asia & 6 & 69.4 & 63.9 & 0.6 & 0.8 \\
Continental S. E. Asia & 5 & 88.4 & 75.2 & 1.3 & 1.6 \\
Insular S. E. Asia & 5 & 154.7 & 135.4 & 1.9 & 1.3 \\
Pacific & 1 & 37.1 & 36.0 & 0.1 & 0.3 \\
\hline Latin America and Caribbean & 33 & 992.2 & 918.1 & 7.4 & 0.8 \\
\hline C. America and Mexico & 7 & 79.2 & 68.1 & 1.1 & 1.5 \\
Caribbean & 19 & 48.3 & 47.1 & 0.1 & 0.3 \\
Tropical S. America & 7 & 864.6 & 802.9 & 6.2 & 0.7 \\
\hline Total & 90 & $1,910.4$ & $1,756.3$ & 15.4 & 0.8 \\
\hline
\end{tabular}


Table 2 Rate of increase of greenhouse gases [5]

\begin{tabular}{lcc}
\hline Gas & Concentration & Rate of Increase \\
\hline Carbon dioxide & $345 \mathrm{ppm}$ & $0.4 \%$ per yr. \\
Methane & $1.65 \mathrm{ppm}$ & $1.1 \%$ per yr. \\
Nitrous oxide & $305 \mathrm{ppb}$ & $0.2 \%$ per $\mathrm{yr}$. \\
CFC-11 & $220 \mathrm{ppt}$ & $5 \%$ per $\mathrm{yr}$. \\
CFC-12 & $380 \mathrm{ppt}$ & $5 \%$ per yr. \\
\hline
\end{tabular}

Source: NRC, Current Issues in Atmospheric Change (1987)

\section{Social Sustainability}

Although a minor segment in this paper, social sustainability is just as essential in keeping a country healthy and smooth running as economic and environmental sustainability is. Administrations must balance economic sustainability with that of social sustainability. If proper attention is not paid to a country's population, people will be left behind, and standard of living in the country will take a hit as a result. Therefore, governmental planning has to ensure the people are not forgotten and they are appropriately taken care of, with emphasis on provision of healthcare, education and a systematic transportation system which will in turn result in improved levels of productivity of the country and its people.

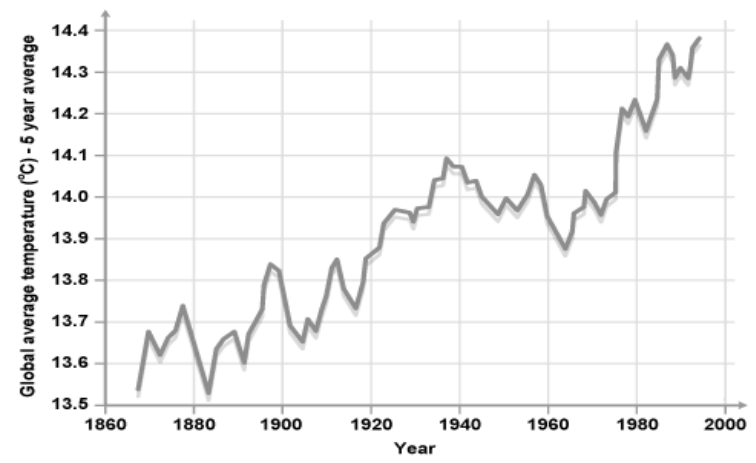

Figure 3 Increase in global average temperature [6]

\section{WHY IS SUSTAINALBE DEVELOPMENT NECESSARY?}

Firstly, whether it is an individual or corporation, sustainability is imperative to remain relevant. If a corporation becomes irrelevant, it will fall behind the respective industry and face natural extinction. Secondly, sustainability is necessary for survival. If a corporation does not manage its resources properly, it will not have a sustainable model and thus, it will in time face extinction too. Thirdly, sustainability is necessary to remain competitive in the respective industry. Hence, it can be said that to remain sustainable, one should remain relevant to both the industry it is a participant of, and to the society it produces goods and services for.

Relevance stems from necessity. And necessity is derived from what society desires. As such, production should aim to be relevant to the target audience. For instance, medical inspection with minimum or no pain is universally desired. During the 1980s, endoscopic inspection was extremely painful because the tube (?) carrying the camera was so large in diameter that a patient would fear having to come back for a second inspection. From the 1990s, the system has seen much improvement, as the tube has become so slender that patients do not feel any pain during inspection.

\section{HOW TO ACHIEVER SUSTAINABILITY?}

\section{Achieving Economic Sustainability}

Having established the importance of economic growth to a country's development, the benefits of growth can now be explored. An increase in growth will enhance the government's ability to invest more capital into improving infrastructure so as to encourage Multinational Corporations to set up shop and invest in the local economy. Furthermore, governments will be able to invest capital into improving education standards in the country, by setting up better-equipped schools and increasing the number of world-class universities. Healthcare should also be a major concern that needs addressing by governments, by providing substantial subsidies for essential vaccinations and setting up state-of-theart hospitals to ensure their workforce and population in general is kept healthy and productive.

When considering economic sustainability, attention must be paid to natural resources - the root of majority of economic activity. For decades, corporations have extracted natural resources such as coal, crude oil and natural gas with no consideration for the environment or the imminent impact it has on future generations. Only recently has it been stressed that natural resources are fast depleting, and at the rate it is going, it will not be long before essential natural resources would have been exhausted, and upcoming generations will struggle to meet their basic needs. This therefore shows, sustainability has not been at the forefront of governmental planning as people have been living for today, without consideration for the future. There has to be a change in mentality amongst people and administrations, to shift their focus to achieve a balance where both economic development and economic sustainability is achieved. Then only will we truly see the needs of the present being met, while keeping in mind the needs of future generations.

\section{Achieving Environmental Sustainability}

Achieving environmental sustainability is an endeavor that stretches generations, keeping in mind the need to maintain an ecological balance. Production has to be careful not to damage the environment more than it already has, and more importantly, at a faster rate than the environment's ability to repair itself. 
Severe environmental regulations are forcing automotive manufacturers to improve the design of fuel injection nozzles to be smaller in size and to have improved accuracy. Fuel injection nozzles are getting finer day-by-day to ensure better fuel efficiency. This ensures lesser carbon emission into the atmosphere.

Furthermore, reliable, clean and renewable sources of energy are key to environmental sustainability. The need to shift focus away from coal and crude oil, and introduce solar power and wind energy for example, is a welcomed move taken by many countries. Furthermore, the production of electric cars from large carmakers such as Mitsubishi and Nissan is paving the way for a cleaner environment and air quality, by reducing the dependency on petrol and diesel fuel. Thus there is a need to increase awareness and investment, so as to increase innovation in developing technology that is able to support these renewable sources of energy and distribute it to households on a large scale.

By keeping the health of the environment at the at the forefront of governmental planning when considering growth and development measures, countries will pave the way for sustainability and future generations will be able to reap the benefits of a healthy planet, good quality of life and renewable sources of energy which will last them for generations to come.

\section{Achieving Social Sustainability}

Every government faces the tall task of satisfying the population it serves. It is important to ensure that living standards are paid attention to by governments. This involves a continuous effort to improve town planning by developing adequate housing, building well-connected roads and constructing an enduring public transportation system such as the London Underground system or the New York Subway system. By providing such essentials to the public, governments will be able to improve the standard of living in their country. Considering the sheer volume of cars in Bangladesh's capital, Dhaka, an underground train service would benefit the country greatly, eliminating the pains of traffic congestion and traffic accidents.

Another step to attain social sustainability is to ensure a balanced distribution of income, thus gradually eradicating poverty. A widening income gap will cause social strife, and that will hamper both the social and economic balance in a country. Therefore, it is important to ensure the poor do not get poorer while the rich get richer. It is necessary to distribute income as equally and fairly as possible so as to improve the overall standard of living in a country.

In one of the OPEC summits, the Prime Minister of Singapore, Mr. Lee, delivered a speech addressing the issue of sustainability, and it is important to highlight some of his key points that are relevant to this paper:

Government will carry out the planning for sustainable development and prepare the platform Governments should draw the long-term national plan, set guidelines and facilitate the execution of such a plan, by removing hurdles and bottlenecks such as any excessive legal or governmental redtape.

Industrialists, mainly within the private sector, will execute such plans - Private sector firms should join hands with the public sector and the government's planning agencies to start production facilities and industries to generate income, wealth and prosperity. I would like to add - Engineers will be carrying out innovation, production and finally will carry out productivity improvement.

\section{ROLE OF ENGINEERS IN SUSTAINABLE DEVELOPMENT}

Engineers are involved in the innovation and production of goods and therefore play a vital role in ensuring sustainable development. Without their planning and innovation, future generations will run into severe problems.

It is important to note that Engineering is a discipline that cultivates in its students analytic and problem solving skills essential to their profession. This skill set can be crucial if well utilized in governmental planning to create a sustainable economy and environment. Thus, it is no surprise that 70 percent of cabinet members in the government of Singapore are Engineers, Architects or Mathematicians, as they are trusted to plan for the future.

Innovation has to be paid special attention to by engineers across the world. With it, there will be an improvement in efficiency of production. This is necessary as innovative ideas such as the introduction of battery-operated cars are a very welcomed step to a cleaner and greener environment. If engineers continue on the path of innovation to develop relevant products needed by societies, keeping the economy and environment in mind, the three main aspects of sustainability discussed in this paper will slowly come to fruition and the dream of a sustainable future for the generations to come will be realized. Therefore it is imperative that engineers continue learning the fundamental principles of their subject and embrace the skill set that comes with it. They can then cooperate with industrialists, governments and economists to create a global impact, whereby everyone will work towards a common goal - sustainability.

\section{ROLE OF MECHANICAL ENGINEERS IN SUSTAINABLE DEVELOPMENT}

Having established the general role of engineers in sustainable development, it is important to now highlight specifically, the role of mechanical engineers in sustainable development. 
Mechanical engineering is apparently considered a discipline mainly designed to be dealing with machines and mechanical systems. If we take a closer look at the roles and responsibilities of mechanical engineers, this discipline can be considered as the merging point of all other engineering disciplines. For instance, if we think of a machine or a manufacturing unit constructed together by a mechanical engineer, the knowledge involvement or inputs from other disciplines are evident. Inputs are acquired from prior knowledge of other engineering disciplines through experience and exposure, or they are obtained by seeking help from experts in the particular engineering discipline: planning and design are formulated from the mechanical engineering discipline; control and mechatronics systems are inputs from mechatronics engineering discipline; foundation and infrastructure information come from civil engineering discipline; marketing and management input come mechanical or industrial engineering discipline.

Growth of an economy mainly depends on industrial development and the backbone of industrial development is manufacturing. The main contribution in production or manufacturing comes from mechanical engineers. However, if mechanical engineers constantly produce goods using outdated technology and cannot produce goods that are relevant (meet the needs and desires of society) presently, then the whole manufacturing system will be unsustainable. For instance, Korea was once producing certain components of the iPhone, which was the most technologically advanced phone at the time of its release. On one hand, Korean producers became the master of the latest manufacturing technology, and they combined their newfound expertise with innovation to become the strongest competitor of the iPhone today. China, the assembler of the iPhone, has also started to produce their own brand of telephone products, which are almost of the same quality or even better in some aspects as compared to the famed Apple iPhone. Unfortunately, as USA has only been involved in design, they have lost their edge in manufacturing technology. Thus, they have had a gradual plunge in competitiveness, which has resulted in them losing their economic supremacy, with China breathing down their neck as the $2^{\text {nd }}$ largest economy.

\section{Thus, the main roles of engineers are:}

i. Engineers need to carry out production; they need to be involved in both production planning and financial planning. Planning without the involvement of engineers is likely to bring problems and in most cases failure.

ii. Engineers need to be actively involved in national planning for sustainable development. As mentioned above, Singapore's success can be pointed at the fact that $70 \%$ of the cabinet members are engineers, architects or mathematicians. The Prime Minister himself has a degree in Mathematics from Oxford. It is also interesting to note that one of the past Prime Ministers of Japan was engineer from Tokyo Institute of Technology, thus there is no questioning the positive impact engineers have on governmental planning.

iii. Engineers also need to be innovative Innovation is the key to survive. Corporations need to remain competitive by developing products superior to that of their competitors.

iv. Developing relevant products - Application of innovative ideas allow us to remain relevant by developing necessary products that are desired by society, or that are necessary for advancement in standard of living.

v. Improving efficiency in production Innovative ideas will lead us to achieve better products with high efficiency and productivity and ultimately more economic benefit. With more efficient production methods, resources will be better utilized, therefore making production more sustainable.

vi. Tackling problems which cause ecological or health problems - Innovative ideas need to be applied to solve ecological and health issues. For example, current automotive vehicles have two serious problems; exhaust from the automotive engine and casting of the engines produce large amount of $\mathrm{CO}_{2}$ gas and this is damaging the environment. Therefore, the revolutionary idea of removing the engine from cars and introducing battery-operated cars instead, is a very welcomed solution to the problem of global warming.

\section{MECHANICAL ENGINEERING CURRICULULM}

Mechanical engineers need to adopt sustainable manufacturing. There has to be emphasis on teaching innovation so as to bring about sustainability. Innovation will help in problem solving and development of relevant goods, as mentioned earlier. To solve a problem one should be able to first analyze the problem, and then be able apply the fundamental knowledge learned, to solve it. Of course, there is a need to be creative when it comes to problem solving. Thinking out of the box is something that can be encouraged and nurtured in students, so that they may be creative and innovative when tackling problems.

\section{Thus, engineering students should}

\section{learn:}

$>$ The fundamentals of engineering

$>$ Applications of the fundamentals

$>$ How to become creative or innovate

$>$ How to manage for sustainable development

$>$ How to plan for sustainable development

\section{How should all these be nurtured?}

- Strong emphasis should be placed on design 
and fabrication technology:

Students should be taught and trained in design starting from conceptual design, drawing, actual prototyping and finally inspection and performance evaluation.

- Fundamental knowledge of design will equip the students with the ability to conceptualize a product that will meet the functional requirements:

Here, an example can be given of designing a machine for compound/hybrid machining which is capable of performing all machining operations in one setup. Until 1960 one technician operated each machine. Then MIT developed its first NC (Numerical Control) System and Japanese machine tools manufacturer developed a machine with NC controller. From then, a machinist was able to operate more than one machine at a time. In the 1980s, machine tool manufacturers developed machines with multiple purposes, which was called Machining Center. However, all these machining centers were integrating only conventional machining techniques (Turning, milling, drilling, etc.). In 1989, when I joined Makino Milling Machine Co., then the largest machine tool manufacturer, I tried to convince them to develop a machine that can integrate both conventional and non-conventional (EDM, ECM, wire-cut EDM, etc.) machining techniques. They argued that it is not possible because the source of cutting energy is different. I took up the challenge and developed the first ever machine in the world, that has integrated both conventional and nonconventional machining and have internationally patented it.

- As they try to fabricate they will face the actual production problems and they will have to think out of the box to find innovative solutions.

Here I would like to give examples of some challenging projects with innovative solutions:

a) One trainee student who came to NUS for short project from IIT Delhi wanted me to offer him a challenging project for a period of 2 months. I asked him to fabricate a micro shaft that is 50 microns in diameter and $10 \mathrm{~mm}$ long. He argued that it is impossible. I told him that a supervisor would never give a project to a student for which he does not have a solution. So he took 2 weeks to come up with a solution. Then I gave him some clues based on fundamental statics, dynamics and physics of metal cutting. He was so excited that he solved the problem and fabricated the product (Figs. 4, 5, 6 \& 7) in another 2 weeks time [7].

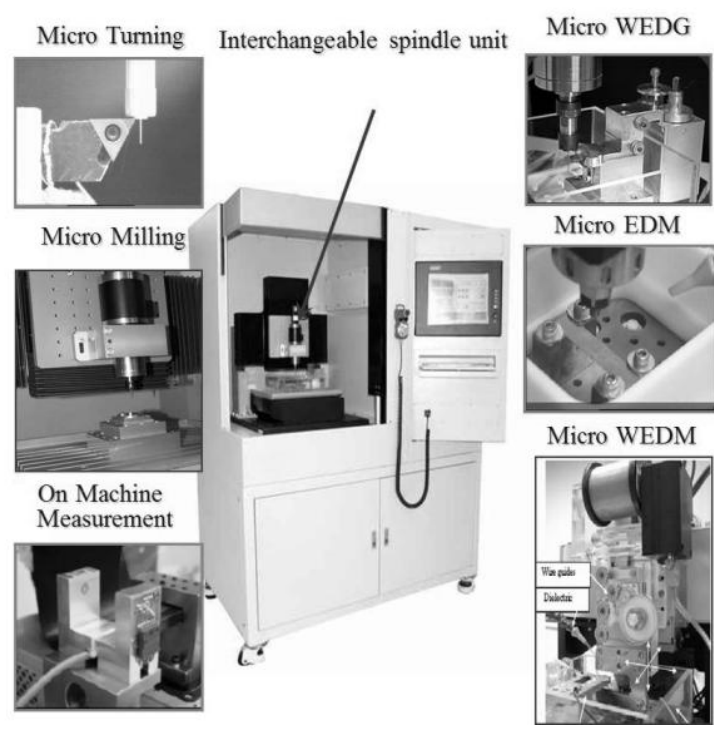

Figure 4. Machine for Compound Micro Machining
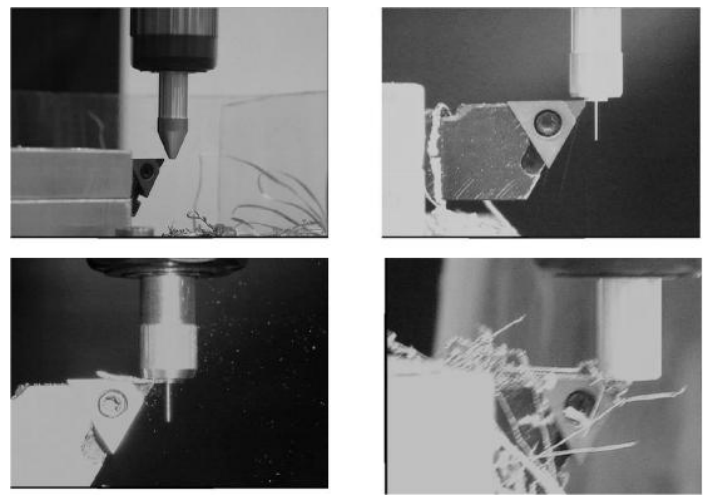

Figure 5. Vertical Turning Process

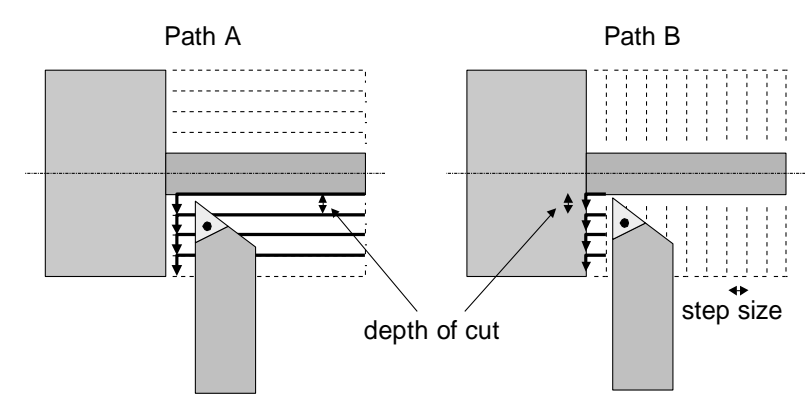

Figure 6. Two Possible Ways to Do Turning 


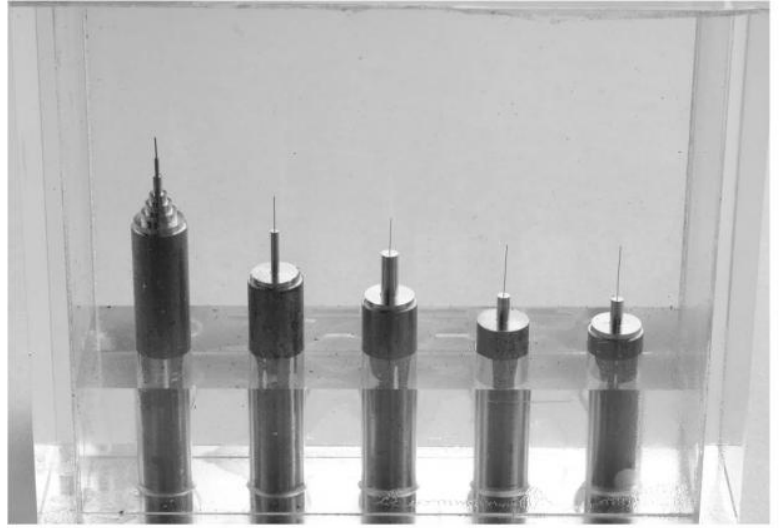

Micro shafts of diameter $50 \mu \mathrm{m}$

Figure 7. Micro Shafts of diameter 50 microns

b) Another overseas student wanted a challenging project for his PhD work. I asked him to machine glass which a brittle material in ductile mode. He too argued that it is impossible. However, when I give him some clues explaining the fundamental properties of brittle materials, he not only managed to unravel the challenge, but he went on to become one of the pioneers in the world on machining brittle materials in ductile mode (Figs. 8 \& 9).
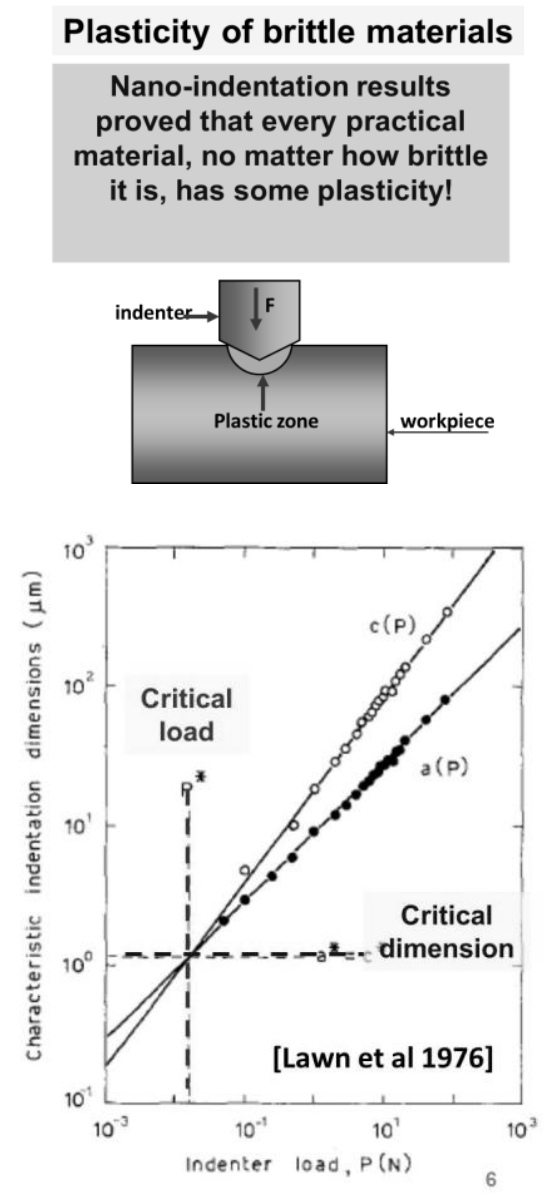

Figure 8. Plasticity of Brittle Materials

\section{- Three modes of machining achieved}

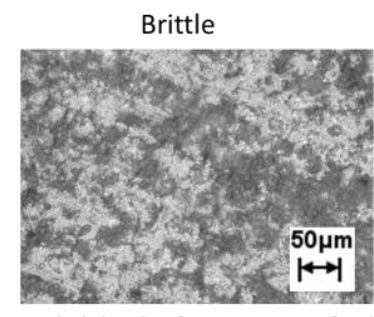

radial depth of cut $=150 \mu \mathrm{m}$, feed rate $=6 \mathrm{~mm} / \mathrm{min}$

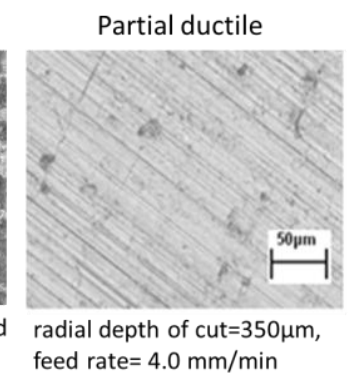

Ductile

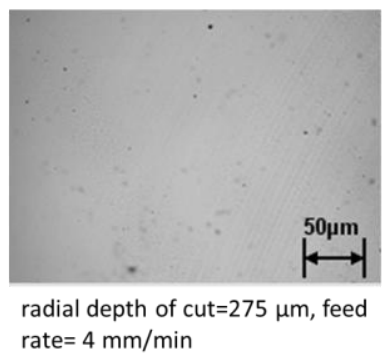

Figure 9. Examples of Three Modes of Machining

c) I asked a Vietnamese student who is currently doing his $\mathrm{PhD}$ with me to carry out simultaneous EDM (electro discharge machining) and ECM (electro chemical machining). Initially he was hesitant, and said it was impossible. However, he was committed to try if I gave him some hints. He has successfully done it and his pioneering work has been published in one of the most reputed Manufacturing Journals in the world, the CIRP Journal (Figs. 10 \& 11).

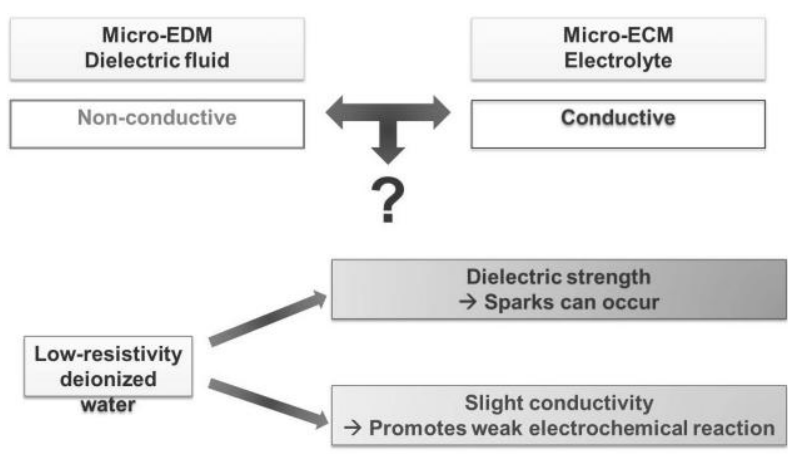

Figure 10. Simultaneous Micro EDM \& ECM Processes 


\section{Surface finish}
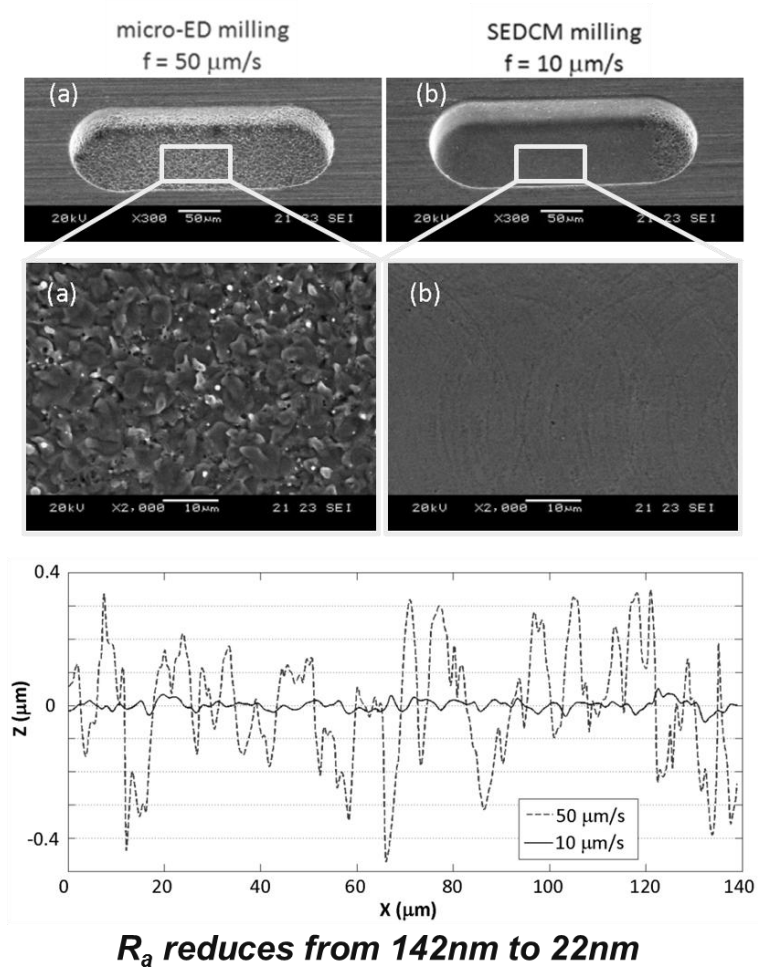

\section{$\rightarrow$ SEDCM milling yields better surface finish}

Figure 11. Nanometric Surface Finish by Simultaneous Micro EDM \& ECM Processes

\section{CONCLUSION}

Industrial development is the main driving force for the mechanical engineers. Therefore mechanical engineers play a pivotal role in economic growth. As such, development is reliant on their actions, productions and innovations.

Mechanical engineers need to get more involved in industrial and economic development of their countries by helping the government to plan for sustainable development.

Mechanical engineering curriculum needs to be updated and upgraded to inculcate innovative minds in future engineers. They should be inspired to be innovate and creative. Once they get the taste of innovation, they will get more interested and enthusiastic about engineering and drive the economy.

To remain in the path of sustainable development, engineers will have to remain vigilant, innovative and creative.

\section{REFERENCES}

[1] Constantine Ziogas, "Economics" Oxford University Press (2008), pg. 121.

[2]http://www.unicef.org/infobycountry/bangladesh_ bangladesh_statistics.html

[3]http://www.env.go.jp/en/wpaper/1993/eae220000 000005.html

[4] http://www.ciesin.org/docs/003-006/003-006.html [5]http://www.bbc.co.uk/schools/ks3bitesize/sci ence/images/globalwarming.gif

[6]http://technorati.com/lifestyle/green/article/ bangladesh-is-sinking-due-to-global/

[7]. Rahman, M, B M A A ABU, T Masaki, T Saleh, Y S Wong and A Senthil kumar, "A Multiprocess Machine tool for compound micromachining". International Journal of Machine Tools \& Manufacture, (2009). (U K).

[8] ARIF, M, M Rahman and $\mathrm{Y} S$ Wong, "Ultraprecision ductile mode machining of glass by micromilling process". Journal of Manufacturing Processes (SME), 13, no. 1 (2011), 50-59.

[9] Minh Dang Nguyen, Mustafizur Rahman, Yoke San Wong, Enhanced surface integrity and dimensional accuracy by simultaneous micro-ED/EC milling, Annals of CIRP, 2012. 